\title{
The Female Athlete
}

Editor

SIOBHAN M. STATUTA

\section{CLINICS IN \\ SPORTS MEDICINE}

www.sportsmed.theclinics.com

Consulting Editor

MARK D. MILLER

October 2017 • Volume 36 • Number 4 